\title{
Los nuevos territorios de la gráfica: imagen, proceso y distribución
}

\author{
New territories of the graphic: image, \\ process and distribution
}

\author{
María del Mar Bernal-PÉReZ \\ Universidad de Sevilla \\ mmarbernal@us.es
}

Recibido: 17 de diciembre de 2014

Aprobado: 15 de junio de 2015

\begin{abstract}
Resumen
La gráfica se encuentra en un proceso de simbiosis con la cultura visual en el que la tecnología de la imagen, la descentralización de la matriz y la adaptación del formato expositivo se funden con el resto de las actividades artísticas. El análisis de las comunidades formadas alrededor de esta práctica configura un puzzle, aparentemente bien encajado, que se divide entre el formalismo y el conceptualismo y entre la idea y el proceso. Las bienales y trienales, a la vanguardia del discurso, cuestionan cualquier concepto que se haya podido asentar con solidez: ante la decadencia del proceso artesanal el mensaje se profundiza nutriéndose de la invectiva provocada por las contradicciones sociales, territoriales y medioambientales para convertirse en un reflejo de la sociedad contemporánea. Comprender la gráfica actual pasa por un ejercicio de aperturismo y un proceso de adaptación al cambio técnico e iconográfico de los sectores implicados. El grabado es ahora un territorio en el que la integración de todas las artes permite cruzar sus fronteras con fluidez.

Palabras clave: gráfica contemporánea, gráfica y cultura visual, grabado experimental.
\end{abstract}

Bernal-Pérez, M.M. (2016): Los nuevos territorios de la gráfica: imagen, proceso y distribución. Arte, Individuo y Sociedad, 28(1) 71-90

\begin{abstract}
Graphic art is in a process of symbiosis with the dominant visual culture in which image technology, decentralization of the matrix and the adaptation of the exhibition format merge with other artistic activities. The analysis of the communities formed around this practice set a puzzle, seemingly well fitted, which is divided between formalism and conceptualism, between the idea and the process. Biennials and triennials, at the forefront of speech, constantly question any concept that were able to settle solidly: because of the decline of the traditional process discourse deepens nourished by invective of social, environmental and territorial contradictions becoming a reflection of contemporary society. Understand the current graph passes through an exercise of openness and a process of adaptation to technical and iconographic change in sectors concerned. Understand graphic art today means an exercise of openness and a process of adaptation to technical and iconographic change in all statements. Now printmaking is a territory where the artistic globalization lets people cross all its borders fluently. Keywords: contemporary graphic art, graphic and visual culture, experimental printmaking.
\end{abstract}


Sumario: 1. La idea frente al proceso, 2. Mestizaje, 3. Reproducción, repetición, reivindicación, 4. Pluralidad, proliferación, velocidad, 5. Adaptación del formato expositivo, 6. Encuentros, circuitos, distribución, 7. Convergencia entre gráfica y cultura visual, 8. Academia, 9. Conclusiones. Referencias.

Este artículo recoge resultados de la investigación de Gráfica y Creación Digital (HUM822) financiada por Consejería de Educación y Ciencia de la Junta de Andalucía. Universidad de Sevilla.

\section{La idea frente al proceso}

La dimensión crítica de inicios de siglo y el principio de innovación que regula las actividades culturales han animado un debate en torno a la gráfica contemporánea cuyo despliegue encuentra resistencias entre los sectores más conservadores. Las peculiaridades de esta evolución demuestran la rápida caducidad de los estudios ya que se trata de un campo que está dejando de existir como tal. En el transcurso de esta deconstrucción se van perdiendo los límites y las características que le fueron propias durante siglos. Como apunta Blas:

Han dejado de existir como tal, al menos en su caracterización tópica: singularidad del artista, bidimensionalidad del producto, exclusividad de la naturaleza de los soportes, multiplicidad de la imagen e inmutabilidad de binomio matriz-estampa. En confrontación con esos parámetros, las nuevas categorías de productos gráficos son el resultado de procesos colectivos y contienen valores potenciales de tridimensionalidad, versatilidad de los soportes, negación del principio de multiplicidad en indefinición del concepto matriz. (...) De hecho, su aproximación, también coyuntural a otras categorías como la arquitectura, la escultura, la fotografía o el vídeo resulta muy significativa (Blas, 2006: 7).

Pese a todos los cambios físicos imaginables, la poética de la gráfica contemporánea permanece y es su motivación fundamental, la de una sensibilización del espectador, la que origina las creaciones más sólidas. En una época en que lo grandioso, lo espectacular, lo monumental se adueña de los espacios expositivos con contundencia, se comprueba una y otra vez que su esencia y su capacidad de expresión permanecen también en las actitudes mínimas, esto es: hacer una raya es un acto gráfico igual que construir un multimedia. Cabría, por tanto, preguntarse cuál es la unidad mínima del arte gráfico, dónde empieza y dónde termina su expansión y si cabe la posibilidad de que esta actualización, incluso, nos conduzca a la revisión de las categorías previas.

La gráfica nació con la idea de reproducir una imagen para su mejor transmisión. Para ello tomó una matriz y usó el papel, lo que sucedió durante mucho tiempo. Pero hoy, una vez alejada la función comunicativa, cada artista funda su proyecto conforme a sus principios particulares utilizando todas las herramientas que se encuentra en el camino. En esta actitud, si el artista no va al grabado es éste quien se desplaza ofreciendo respuestas a medida que surgen las necesidades. En este continuo cambio de posición florecen las teorías encaminadas a dilucidar su esencia. Y su permanencia. Ante la pregunta formulada a Christophe Cherix, comisario de la exposición Print/Out: 20 Years in Print celebrada en The Museum of Modern Art de New York (2012) sobre la posible desaparición del arte gráfico, su respuesta vaticina el final de su identidad singular anunciando un futuro en el cual las estampas serán 
llamadas, sencillamente, arte. En este sentido, la reproductibilidad, la capacidad para distribuirse y su naturaleza colaborativa son los ejes fundamentales.

Analizar este paradigma desde una óptica lenticular parece estar en el origen de tantos contrastes. Son muchos los actores, complejo el escenario y no hay un único director, a lo que se une la multiplicidad de puntos de vista, lo que desemboca en la formación de grupos de distinta naturaleza. Por un lado, encontramos a los artistas contemporáneos, de los cuales unos trabajan con absoluta libertad pero otros han de superar ciertas necesidades económicas o de visibilidad que le imponen limitaciones; por otro lado trabaja un sector amplio de grabadores que se resiste a abandonar los procesos más tradicionales sin intermediación de otras disciplinas; le siguen las galerías y editoras que retienen el aspecto más objetual de la estampa y, por último, las bienales y trienales, a la vanguardia del discurso, que bajo la denominación de distintas tesis, cuestionan cualquier concepto que se haya podido asentar.

En la década de los setenta, Joseph Beuys pronunció en un discurso en el Centro de Arte Walker de Minneapolis que la estampa era una suerte de sostén para la memoria... en caso de que algo diferente ocurriese en el futuro. (Beuys, Klüser Schellman, 1970). Se refería a un futuro, hace ya casi tres décadas, encargado de reactivar una práctica que había comenzado una inquietante deriva y que con el tiempo parece haberse consolidado en la voluntad de ocupar nuevos espacios y profundizar en su mensaje. Este conceptualismo se nutre de la invectiva provocada por las contradicciones sociales, territoriales y medioambientales de hoy y el desbordamiento de cualquier horizonte formal.

Recientemente ha habido una sobrestimación de los materiales y "nuevos" procesos que, bajo el marchamo de la sostenibilidad y propagados por una comunidad virtual importante, han adulterado la gráfica hacia un manierismo tecnológico parecido al que se produjo en el grabado académico del siglo XVII o los primeros años litográficos. Atendiendo a este sector no estaría de más revisar las teorías de W. M. Ivins Jr (1975) y adaptarlas a esta segunda década de siglo ya que para el arte es necesario minimizar semejante prevalencia de lo externo sobre lo interno. La contradicción que produce esta escala de radicalidad procesual queda inteligentemente señalada por Pastor Mellado en sus informes de campo:

Esto nos indica la existencia de un campo problemático en el que tiene lugar una superposición epistémico no correspondiente, que consiste en el empleo de una tecnología gráfica perteneciente a una písteme tecnológica posterior, pero que es considerada desde el diagrama de una písteme tecnológica anterior. Por ejemplo: un uso litográfico de una pisteme fotográfica; o bien, cuando se da el caso de trabajar en un soporte digital pero sin abandonar los límites de una písteme termodinámica (Mellado, 2004, III).

Lo mismo sucede con la actual písteme del fotograbado, por poner otro ejemplo. En muchos casos se trabaja superficialmente una tecnología que hace más de un siglo demostró sobradamente su supremacía técnica con respecto a la reproducción de la imagen, por lo que no tiene mucho sentido convertirla en un nuevo proceso artesanal, sin más. Hay que distinguir entre este grupo una comunidad en la que prima la idea de una gráfica contemporánea que hace pensar, que distingue entre la producción y la creación y que sigue manteniendo puntales fundamentales como la matriz, el soporte 
y la edición pero con imágenes llenas de contenido. Por regla general son artistas que trabajan con editores profesionales, versión contemporánea de los maestros impresores. La importancia de estos especialistas debiera ser objeto de un profundo análisis ya que, seguro que se concluiría la influencia determinante que pueden tener en la configuración de la gráfica actual. (Fig. 1).



Figura 1. Richard Dupont. Phantom, 2007. Aguafuerte y aguatinta, 100.7 x $160.8 \mathrm{~cm}$ Editado por Carolina Nitsch Contemporary Art, New York. Estampador: Gregory Burnet, asistente estampación: Brian Rumbolo New York. Edicion: 12. The Museum of Modern Art.

El grabado es un nicho que proporciona un sentido de unidad usando un elaborado conjunto de términos y procesos que tiende a agrupar a las personas alrededor de las distintas prácticas. Estos colectivos, tales como teóricos, agentes culturales, editores y galeristas o círculos alrededor de ciertos formatos (libro de artista, grabadores experimentales, conceptuales, puristas...) forman un diálogo artístico y social. El prestigioso comisario de arte Edward Winkleman (2009) cuyo trabajo pudo verse en la $53^{\mathrm{a}}$ Bienal de Venecia, los agrupa según determinados niveles asumiendo que hay una estructura de poder dentro y fuera de todas sus relaciones. Esta ordenación afecta a la determinación de qué es y qué no es considerado como gráfica (contemporánea, de vanguardia, de calidad...) y a la vez, producen discursos que significan cosas distintas según quien los reciba:

Hay, por ejemplo, discursos que tienen un ámbito internacional, regional, nacional, y local; discursos que están basados en el medio; discursos que están basados en el concepto; y asi hasta llegar al punto que se podría decir que "el discurso" es un término inútil en la discusión de asuntos prácticos" (...) Pero en realidad no lo es. Cuando se le preguntó a un grupo de galerías (es decir, los miembros del comité seleccionador) que opinara sobre si la Galería X debe entrar en la novedosa Feria de Arte Y, encontraron una razón práctica (por no decir potencialmente económica) que les llevó a la conclusión 
de que no debía ser incluida porque su programa quedaba fuera de "el discurso". Eso no significa que esa galería no fuese de la más alta calidad dentro de su nicho de mercado, sino que no ayudaba a reforzar la declaración artística de las otras ya asociadas a esa feria (Winkleman, 2009).

Esas estructuras de poder o "comunidades invisibles" ha sido la denominación propuesta por Caro y Casanueva (2013) quienes demuestran cómo los distintos ámbitos quedan condicionados extraordinariamente por el componente social. Para subrayarlo es significativa la declaración de Nuria Enguita, co-curadora de la $24^{\mathrm{a}}$ Bienal de São Paulo, cuando pronunció "Y un curador depende, finalmente, de sus contactos" (Enguita, 2014).

\section{Mestizaje}

Con este abigarrado panorama aminora la preocupación surgida hace unos años por encontrar un adjetivo definitorio que acompañase a la gráfica. Se ha catalogado la gráfica expandida como principal calificación, la gráfica virtual, producto de las matrices intangibles, la gráfica radicante e, incluso, la gráfica ataxonómica producto de la complejidad. Continuaron la gráfica intersticial, inter y transdisciplinar referida al grabado como un lenguaje cuyos límites formales tradicionales se han desdibujado. El ámbito anglosajón reorganiza esta nomenclatura estableciendo la gráfica híbrida, gráfica 2.0, gráfica tradigital (tradicional + digital) o gráfica post digital atendiendo a la cultura tecnológica imperante. Pero intentar delimitar procesos cambiantes y reflexionar sobre su naturaleza artística en plena etapa de desarrollo es un asunto complejo. El paso del tiempo va demostrando que, frente a lo sustantivo, las etiquetas pasan pronto al olvido. No obstante expansión y desarrollo tecnológico son los pilares que la sustentan; tal vez con algo de perspectiva histórica y siguiendo rigurosamente los parámetros estructurales de los respectivos campos de actuación podría hacerse una clasificación más estable de lo que ha sido, y no, la gráfica durante estos últimos 25 años.

El grabado es ahora un territorio en disputa. El término, parece finalmente haber sido absorbido por el de obra gráfica y se extiende desde la estampa bidimensional a la instalación, desde los estarcidos urbanos a las impresiones 3D, del fondo del escritorio a la performance o el happening. Tiene copado no solo la gráfica tradicional, sino también la arquitectura, el mobiliario y el bien de uso común. Incluye lo único y lo múltiple, lo valioso y lo gratuito, lo perenne y lo efímero y se extiende por el campo físico y el ciberespacio, por el mercado y el museo, entre la élite y lo popular.

Los artistas y teóricos cruzan las fronteras con fluidez y los proyectos más vanguardistas amplían aún más la definición del medio. Estos modos que cuestionan profundamente la autonomía gráfica y su metodología transdisciplinar, indisciplinada dice José Luis Brea, responden a haberse criado "en los intermedios, fuera de todo programa, en el inbetween" (Brea, 2006: 22). Lafuente Ferrari en 1936 ya identificó, también, el caso de un artista ochocentista en este sentido "Si quisiéramos definir en una fórmula la esencia compleja del arte de Piranesi, podríamos decir que es la obra de un arquitecto con dotes de pintor que concentra su vocación en el grabado" (Crespo, 2014: 312). 
En abril de 2007 la Escuela de Arquitectura y el Departamento de Arte y Arqueología de la Universidad de Princeton celebraron un congreso alrededor del influyente ensayo de Rosalind Krauss Escultura en el Campo Expandido (1979) en el que la autora reflexiona sobre la explosión multidisciplinar que tuvo esa materia y origen de la denominación actual de gráfica expandida. Recientemente han sido revisados los textos de los que participaron en aquel simposio, incluyendo a Krauss: Rememorando el campo expandido supone una actualización del estudio en el que puede comprobarse que los mismos argumentos se globalizan al resto de las actividades artísticas, se extienden al campo gráfico y a la arquitectura, como arte matricial, que queda constituida en la actualidad como uno de los territorios más fértiles para su práctica. En la introducción queda expuesto que expansión, adyacencia, convergencia, intersección, proyección, compenetración y solapamiento son algunos de los términos usados para redibujar las fronteras entre las artes visuales y la arquitectura a la vuelta del siglo XXI. Y expresa: "Si los modernistas inventaron el modelo de una manifiesta "síntesis de las artes" su descendencia posmoderna promovió la semblanza de una fusión pluralista" (Parapetros, 2014: vii).

\section{Reproducción, repetición, reivindicación}

Bajo el sugerente título de Reproducción, repetición y reivindicación la Plataforma Internacional de Arte Gráfico Ingráfica, encabezada por Javier Martín-Jiménez, comisarió una exposición de arte emergente español itinerante por varias bienales europeas durante 2010 y 2011. Las líneas de su discurso expositivo se argumentaron alrededor de la "reproducción, entendida como la copia de un original, normalmente por medios mecánicos (tórculos, fotocopiadoras, plotters...); la repetición, considerada un valor intrínseco al arte múltiple (...) y la reivindicación: asumida por un lado como defensa de la nueva producción y por otro como medio de ideas sociales o políticas" (Ingráfica, 2010).

Las tres acciones, extendidas a sus objetos directos, se conforman como los agentes de esta metamorfosis. En primer lugar, la matriz (modificada, desplazada y ampliada) se extiende a todo aquello capacitado para estamparse. Se incluye su desaparición física, matrices intangibles, en tanto la existencia de los archivos digitales o la misma red social considerada como matriz.

En segundo lugar, la seriación ha comenzado a desprenderse de su función múltiple como fin último para asumir una función generadora de objetos. En el I Foro de Arte Múltiple, la reflexión de Jesús Pastor sobre esta nueva identidad establece que está más interesado en hacer grabado que producir una estampa. "Ya no podría, quizás, llamarse grabado. Pero sí podemos crear la imagen con, y desde, el grabado" (Pastor, 2012:67); igualmente la edición tiende a desaparecer en base a la revalorización de lo único, como demuestran la actualidad del monotipo y la estampa única. En el extremo opuesto también sustenta esta idea la revalorización de series desmedidas en una manifiesta apreciación de la solvencia comunicativa de este arte. Un ejemplo significativo es la obra de Ai Weiwei, con la realización de tres libros (Negro, Blanco y Gris) en una edición de tres mil ejemplares cada uno. Según su autor "los libros fueron un medio de comunicación del arte, conceptual y literalmente."(Weiwei, 2012). (Fig. 2). 


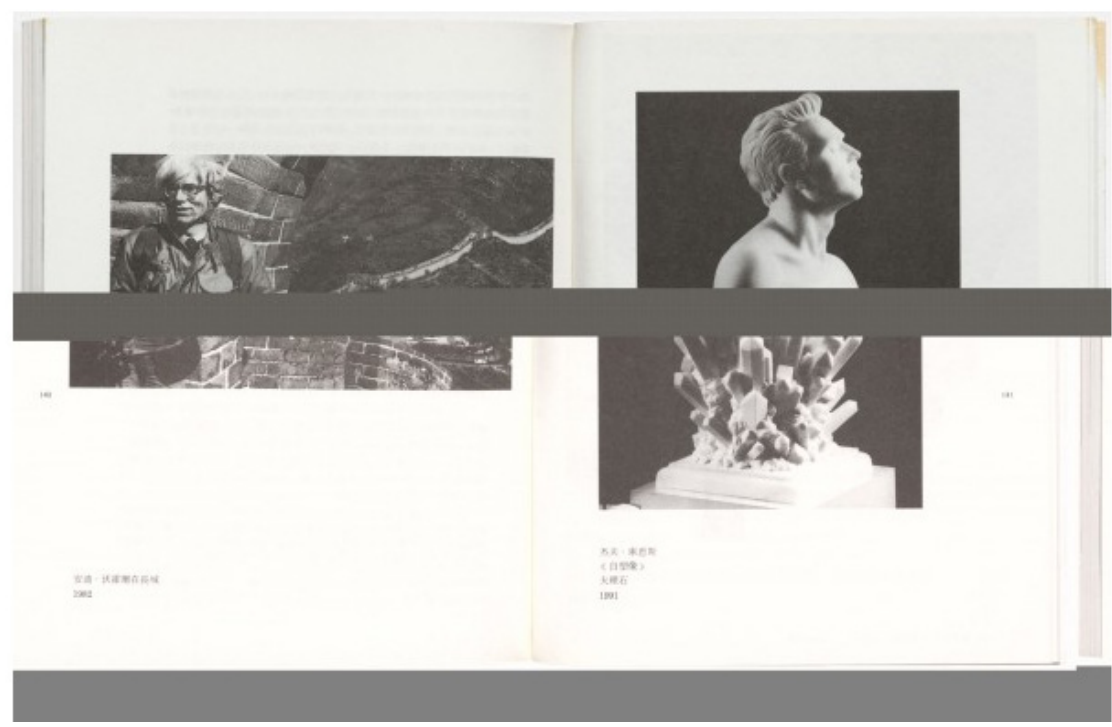

Figura 2. Ai Weiwei, The Black Cover Book, 1994, Libro de artista. Edita: Tai Tei Publishing Company Limited, Hong Kong. Estampador: desconocido, Hong Kong. Edición: 3,000. The Museum of Moderm Art, New York.

Por último, al disminuir el proceso artesanal el artista se concentra en un plano más intelectual y comienza a insistir en el poder reivindicativo del arte gráfico más que a su orientación estética. Brea precisa en sus ensayos que lo que está en juego es la forma de abordaje a las prácticas de producción de significado y efectos culturales, haciendo una interesante propuesta de fusión entre disciplinas:

Se trata en ello de moverse a ritmo de $n+1$ poniendo a prueba cada acoplamiento cada ensamblaje, cada agregación posible. No de descartar nada, no de negar nada: sino de asegurar el máximo de riqueza y densidad conceptual en la mirada analítica que escruta y valora (Brea, 2006:21).

En este sentido es importante reconducir la gráfica a sus fundamentos de un "arte para todos" aprovechando su capacidad máxima de distribución. Podemos apoyar éste último punto en las reflexiones de Martínez Moro (2008) para quien la transgresión de la metodología del grabado carece de importancia en la denuncia social, o en las afirmaciones del historiador argentino Fernando Davis dentro de su análisis de la estampa de los años 70:

El grabado estableció sucesivas instancias de filiación e intercambio con los medios de comunicación, desde la apropiación y manipulación de las concepciones icónicas de los media y la experimentación con técnicas, soportes y dispositivos del dominio de la gráfica industrial, a la redefinición de las tradicionales condiciones de circulación de la obra impresa de cara a una recepción ampliada de las imágenes (Davis, 2005: 8). 


\section{Pluralidad, proliferación, velocidad}

Octavio Paz en el emblemático texto de Actualidad Gráfica describió también el fenómeno relativo a la velocidad con que aparecen, se propagan y repiten las tendencias artísticas en nuestra época:

En los últimos veinte la mayor parte de las novedades son versiones recién maquilladas de movimientos de hace cincuenta o sesenta años. La vanguardia gira en el vacío y en torno a si misma; ha dejado de inventar, pero, incansable, se repite... En suma, pluralidad, proliferación, velocidad: el aquí y el allá, el ayer y el hoy, tienden a confundirse (Paz, 1979: 12).

Así que al carácter de reproducción, la capacidad de seriación y el espíritu de reivindicación hay que unir las características de un mundo globalizado en el que todos los artistas, y sus peculiaridades, se exponen a la velocidad vertiginosa de la red. En esta diversidad el grabado encuentra la mejor forma de distribuirse con la ayuda del lenguaje audiovisual. Méndez Llopis (2010) ofrece un interesante argumento para el debate ya que previene de que, al tratarse de una actualización tan incesante, pudiera suceder que quedase sin asimilar. Nos encontramos por tanto en una puntillosa situación que colinda no solo con la revolución de una disciplina, sino también con las modas tecnológicas que nos envuelven:

La inconsistencia conceptual, la incomprensión y la fugacidad de conceptos que no logran permanecer más que la duración de su sensación (...) Una comodidad innata a las herramientas digitales que hasta cierto punto esclaviza, causando un abandono de anteriores procesos creativos que son desechados antes de ser revisados y cuyos resultados son menospreciados apriorísticamente, nublados por la inmediatez (Méndez, 2010:188).

\section{Adaptación del formato expositivo}

La gráfica contemporánea se caracteriza por acoger un rango de formatos amplio en el que el soporte tradicional queda deflacionado. La tecnología traspasa la barrera bidimensional ofreciendo al artista mayores posibilidades de expresión y favorece la producción de soportes, espacios y acciones que amplían la percepción de la obra desde lo estrictamente visual a lo sensorial: lo óptico va ampliándose en pro de una percepción háptica (Gibson 1966) que incluye el resto de receptores sensoriales (oído, tacto, gusto, olfato) y está estrechamente relacionado con el movimiento del cuerpo que se adentra en la instalación.

En esta preocupación por el habitar la obra de arte, la instalación es uno de los formatos expositivos más utilizados. Mantiene el acondicionamiento artístico de un espacio que interactúa con el espectador modificado con la intervención de impresiones de cualquier tipo. 


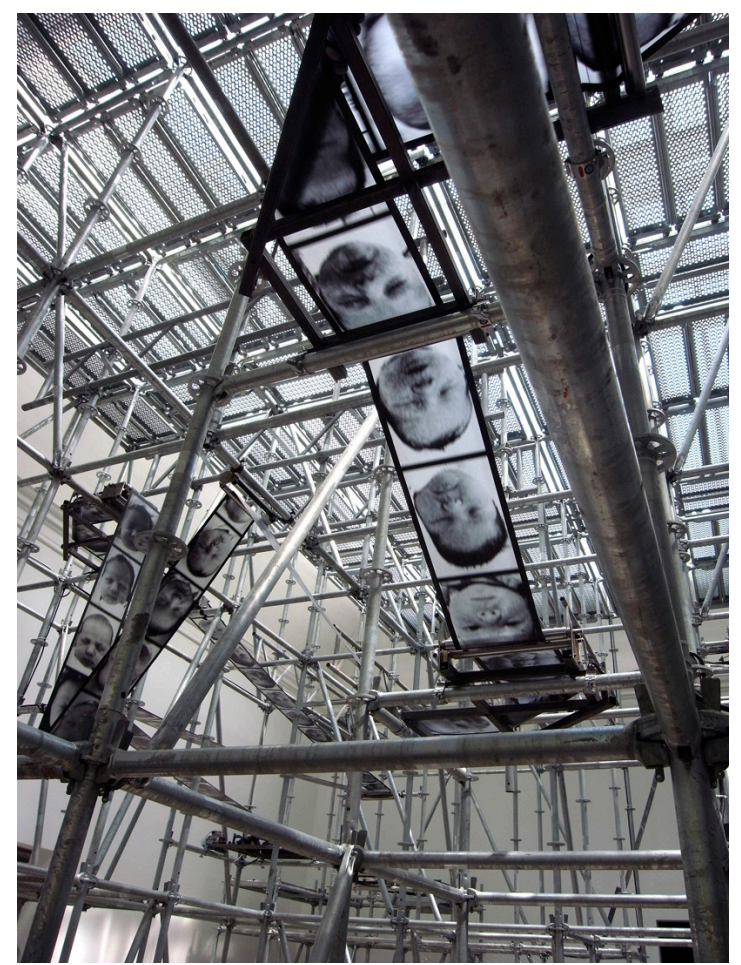

Figura 3. Christian Boltanski Chance, 2011. Detalle instalación. Dimensiones variables. 54 Bienal de Venecia Curada por Jean-Hubert Martin, Pabellón de Francia.

El artista que planea su instalación ofrece una alternativa para el grabado con el uso del espacio. En el proyecto las impresiones de toda índole e, incluso, las matrices, juegan un papel protagonista y emanan de la fase de producción consistente en diseñar, tallar e imprimir y estampar. Posteriormente se montan los componentes ajustando y revisando la configuración final. En la entrevista que Emze Emmons realizó al artista Nicola López se destacaba lo siguiente:

El elemento impreso, a menudo, no se refiere ni encaja en la forma que había imaginado, pero hará algo nuevo y sorprendente que acaba dictando grandes aspectos del resultado final. [En una instalación] las relaciones de control, riesgo, oportunidad, orden, accidente $y$ descubrimiento es central en el arte de las decisiones (Emmons, López, 2008).

Nancy Spero, John Hitchcock, Roy Wainston o Isaac Tin Wei Lin son otros ejemplos muy interesantes de artistas que trabajan con la instalación y el grabado, diseñando minuciosamente cualquier proyecto de envergadura. Esta forma de trabajo se contrapone a la anterior revolución de importancia en el grabado, cuando las propuestas de Stanley William Hayter se dirigían a la construcción de una gráfica basada en la experimentación y en la que las distintas respuestas plásticas aparecían según la evolución del proceso. (Fig 3). 
Por otro lado, el surgimiento del happening con Allan Kaprow en los años sesenta facilitó que los espectadores participaran apoyando las diversas causas sociales de las que ya empezaba a comprometerse el mundo artístico. Este arte de acción es encabezado por artistas de corte vanguardista con un marcado significado de disenso. La artista Aleksandra Mir realizó Venezia (all places contain all others) expuesta en la XX Bienal Internacional de Arte de Venecia en 2009. En ella, Mir yuxtapone imágenes de lugares conocidos con el título de la ciudad italiana creando un centenar de postales turísticas, en una edición de diez mil ejemplares cada una. Las postales se ofrecieron como recuerdos gratuitos o con la intención de que fueran enviadas por correo por los visitantes en los buzones que se colocaron en los jardines de la exposición. El arte postal también ha encontrado en la gráfica las herramientas más efectivas para su creación: lo múltiple, la edición en formato papel -o similar- la transmisión de un mensaje, la capacidad de reproducción (fotomecánica, digital o manual) el concepto de ephemera y la trasgresión de los canales tradicionales de distribución artística mediante el sistema de correos. Fue originado por algunos artistas del movimiento Fluxus en los años sesenta y aún continúa vigente en el arte contemporáneo.

La estampa performativa provoca una situación de rechazo al mercantilismo de una gráfica hiper-estetizada sustituyéndola por algo más comprometido y conceptual. En un regreso a la gráfica tradicional (impresión y seriación) y a la representación teatral, los artistas performáticos, atraídos por la capacidad de conseguir una impronta de su acción, in-corporan formas novedosas de estampación a partir de, o sobre, la propia anatomía.

Un primer tipo de acercamiento entre ambos campos consiste en convertir el cuerpo en la matriz de la acción. Desde este punto de vista una de las más bellas performances es la conocida Anthropometries of the Blue Period, de Yves Klein (1960) cuyas modelos embadurnadas del IKB dejaban su impronta en grandes superficies. En esos años muchas artistas utilizaron su cuerpo para la militancia feminista innovando con procesos destinados a llamar la atención. Ana Mendieta en Body Prints (19731977) abanderó el problema de la identidad femenina cuestionando las convenciones que determinan el rol individual y social -múltiple- de la mujer cubriendo su cuerpo tintado de sangre con un sudario negro que luego quitaba para dejar al descubierto la impronta roja de su anatomía desnuda. Regina Galindo va un poco más allá realizando una acción con sangre humana para centrar sus intervenciones en los problemas de la sociedad guatemalteca sobrecogida por las violaciones y otras injusticias propias de la dictadura. En la obra ¿Quién puede borrar las huellas? (2003) Galindo moja sus pies en sangre imprimiendo una hematografía que utilizaba su cuerpo "no como cuerpo individual sino como cuerpo colectivo, cuerpo global. Ser o reflejar a través de mí, la experiencia de otros; porque todos somos nosotros mismos y al mismo tiempo somos los otros" (Reilly, 2007:140) Para ello la repetición -seriación- de la huella era imprescindible. Por subversiva cabe citar también la performance Kiss my Royal Irish Ass (K.M.R.I.A) de Cheryl Donegan en la Rosen Gallery de Nueva York, colocándose papeles en las nalgas tintadas en verde para estampar dibujos en forma de trébol, símbolo nacional de Irlanda (Donegan,1992). (Fig. 4). 


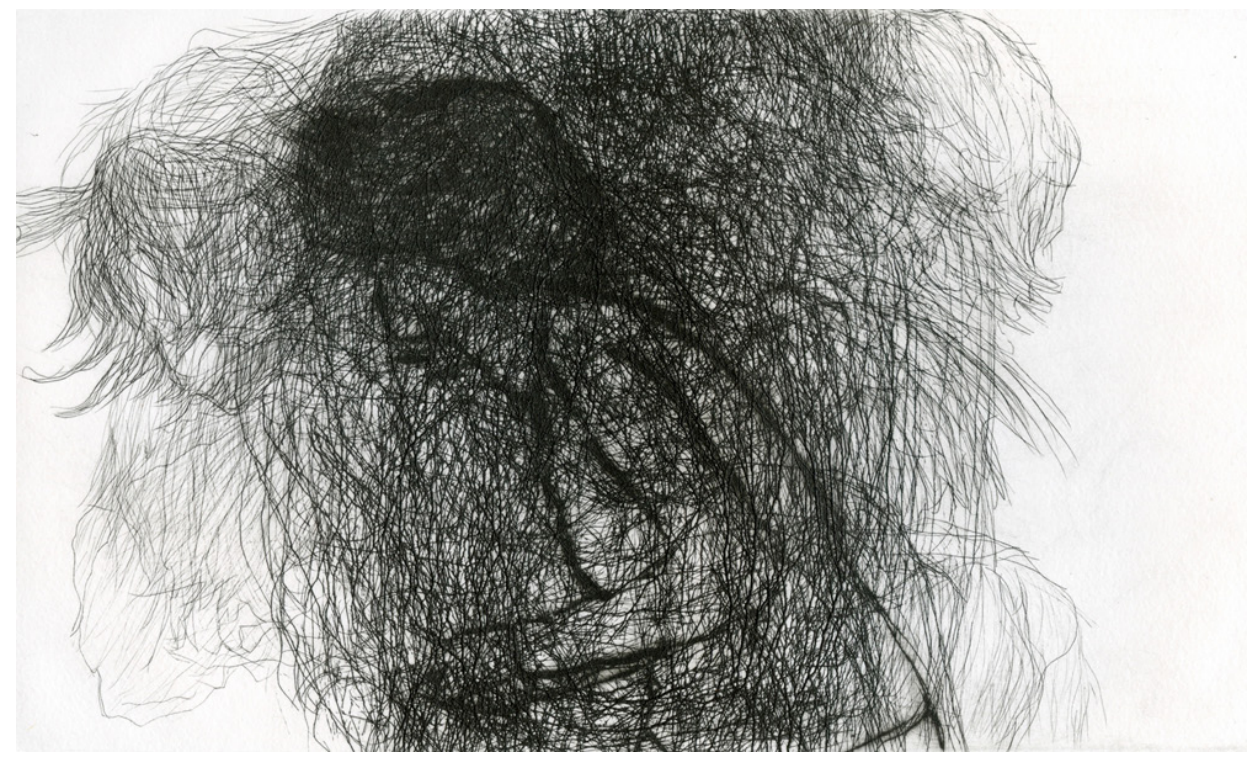

Figura 4. Cheryl Donegan, Kiss my Royal Irish Ass (K.M.R.I.A.) 1992. Fotograma del vídeo de la performance realizada en la Andrea Rosen Gallery, New York.

En segundo lugar, de naturaleza más traumática son las heridas y marcas en el cuerpo que dejan su impronta en el papel. Un ejemplo es la obra Trademarks de Vito Acconci quien en 1971 se sentó delante de una cámara para morderse el cuerpo, entintar esas huellas y obtener una estampa.

Un tercer grupo engloba aquellas actuaciones que utilizan el cuerpo como soporte de la acción. Es digna de mención la obra Borned in URSS del artista Valeriu Schiau en la V Bienal Internacional de Grabado Experimental (Rumania, 2010) en la que denuncia mediante la impresión en su cabeza y torso los retratos de las víctimas de la dictadura de Stalin.

Las nuevas tecnologías van dando paso a un género en el que lo audiovisual y lo transmedia es mezclado con el cuerpo humano para dar lugar a situaciones de intensa repercusión estética. El texto Digital performance a history of new media in theater, dance, performance art and installation, (Dixon, 2007) presenta en su indagación asuntos como la performance on line, la performance interactiva, robots, cuerpos virtuales, etcétera. Una realidad que nos describe los derroteros por los que, muy probablemente, discurrirá esta forma de expresión.

Otra consecuencia natural de la gráfica en su maridaje con las nuevas tecnologías es la animación. Su capacidad de seriación permite muchas imágenes a partir de una sola matriz, que se desplaza físicamente para generar un movimiento, lo que acompaña al conjunto general de imágenes distintas. Pueden destacarse los extraordinarios trabajos en punta seca de la joven surcoreana Kakyoung Lee que se encuentran en los fondos de la colección McNay, el Metropolitan de Nueva York o la Library of Congress de Washington. Como ejemplo citamos la obra Dance, Dance, Dance (2011). (Fig. 5). 

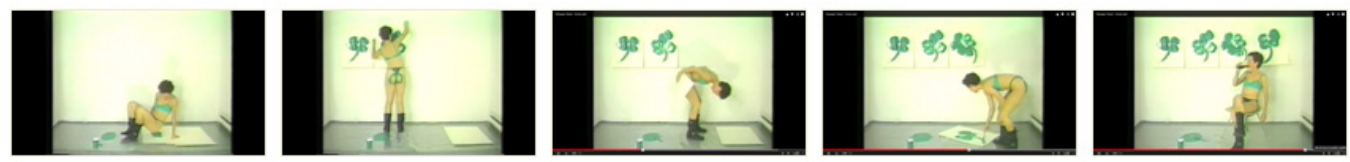

Figura 5. Kakyoung Lee, Dance, Dance, Dance, 2011. Animación en HD, 2 min. 20 seg., blanco y negro. Sonido por Natacha Diels. Edita: Ryan Lee Gallery, New York. Estampa: Kakyoung Lee, asistente de estampación Tatiana Simonova. 342 estampas en punta seca, 53 x $38 \mathrm{~cm}$ Edición de 1/1. Suite de 10 estampas en edición de 8. Ryan Lee Gallery. New York.

Mirta Kupferminc y Mariana Sosnowski realizan en el año 2004 En Camino, una serie de aguafuertes de extrema complejidad y belleza que describen la cruda realidad de la emigración en Argentina. Las imágenes originales fueron estampadas en blanco y negro aunque muchas de ellas están iluminadas a mano. El artista Marcus Rees Robert describe la sensación de un grabador cuando transterra su actividad gráfica a otros formatos ya que, sintiéndose poco satisfecho con el tipo de grabado tradicional, comienza a realizar cortos de animación:

Aunque el film no tiene la misma tactilidad de un aguafuerte o un libro, si tiene la capacidad de desarrollarse de una imagen a otra, algo que no permite el aguafuerte (...) una serie de grabados o un libro de artista no pueden jugar con la anticipación, la tensión y los ecos de las imágenes previas de la misma manera que una película. En realidad, yo no quiero hacer películas, yo quiero que mis imágenes se muevan, pero no como en una película donde una imagen sigue a otra siguiendo la lógica de la cámara. Yo quiero que mis imágenes se sucedan de una a otra con la lógica de la poesía o con el desorden del caos (Tala, 2009: 98).

Su obra más conocida es Letters to a man at the border derivada del libro de artista $A$ room in Portbou en el que relata el suicidio de Walter Benjamin para evitar ser apresado por los nazis. En este modo de trabajo debe prestarse especial atención a la publicidad y los videoclips en los que la gráfica ha incursionado con excelentes trabajos. Buenos ejemplos son los de Vinicius Sánchez, Afoxoque (2012) o Nei Need de John Leamy (2013). La sensorialización de la estampa llega también en interesantes trabajos en los que es la misma tinta la que produce el sonido. (Rodríguez Naranjo, 2012).

Finalmente hay que mencionar la estampa tridimensional que llega mediante el uso de impresoras 3D, por la impresión en soportes más allá del papel como cerámica, metales u otros (Fig. 4) o como resultado de collages y ensamblajes. Éste último apartado encuentra su origen en los años 50 del siglo XX cuando Dubuffet creó unas serie de collages con alas de mariposa y unas litografías que denominó Assemblages d'empreintes. En la gráfica se rompe con las connotaciones residuales de los objetos encontrados aunque incluye todo tipo de materiales y formas imaginables. La serie, entendida como parte del proceso y no como múltiplo, es un factor determinante del resultado final. Anish Kapoor, Jan Hendrix, Marlene Oliver, o Martínez Moro son algunos ejemplos. (Fig. 6). 


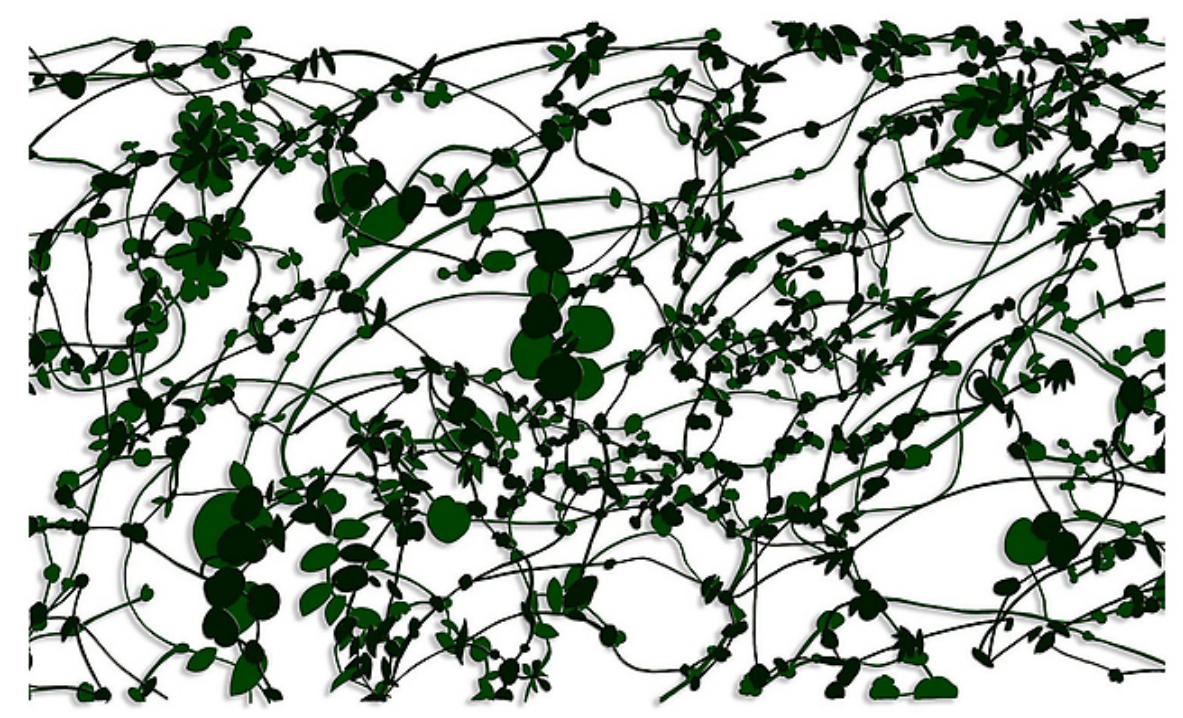

Figura 6. Jan Hendrix, Eclipse IV, 2006. Superposición de acero a doble cara recortado y lacado, 120 x $200 \mathrm{~cm}$. Publica: Jan Hendrix y Factum Arte. Edición de 6 ejemplares editado por Galería La Caja Negra (Madrid).

\section{Encuentros, circuitos, distribución}

Por regla general, la gráfica suele exhibirse en las ferias más importantes de arte como una disciplina más, pero hay casos que suelen distinguirla con un área específica en su programación. Un ejemplo de ello, a nivel europeo, sería Basel Edition como sección de Art Basel, una de las más acreditadas. Otro tipo son aquellas muestras nacidas con esta configuración exclusiva como Multiplied Art Fair, organizada por la casa de subastas Christie's en la capital inglesa que, estratégicamente, la hace coincidir en calendario con Frieze London. Sobresale también la London Original Print Fair, patrocinada por la Royal Academy, que cuenta con el mayor prestigio, y volumen de ventas, de todas. Dado que Londres y París representan el principal montante de transacciones económicas en el mercado global del arte (McAndrew, 2014) haremos especial mención en estos breves ejemplos de la recién nacida, y prometedora Soon (Salon de L'oeuvre originale numérotée) de París, aunque por su corta andadura aún es pronto para determinar su importancia dentro del panorama artístico.

Pero existen muchas más. Como es natural no se pueden referenciar todas en este artículo ya que se aleja del presente estudio. Pero analizar la situación de la gráfica en estos eventos, abriría una interesante línea de investigación en un doble sentido: desde la estructura del mercado se identificaría quiénes son los principales agentes comercializadores de obra gráfica y el peso relativo de cada uno de ellos sobre la facturación global del sector. Es decir, se trataría de distinguir con claridad los roles y el protagonismo de proveedores (artistas), distribuidores (sector editoras, sector galerías y ferias, sector responsables de casas de subastas, sector instituciones) y 
clientes finales (coleccionistas). Resultaría también significativo conocer la realidad de la distribución de la gráfica en el mercado total para tomar conciencia de la necesidad de emprender acciones para promover la generación, difusión y conservación del patrimonio gráfico. Todavía parece que el sector debe ser estimulado por parte de muchos de los agentes implicados. Y como consecuencia de esto pudiera apuntarse en qué manera afecta -y si afecta- esta estructura a la configuración final de la obra gráfica.

La aparición de atributos como poligrafía (Puerto Rico) o experimental (Rumanía) en la denominación de bienales y trienales de grabado, agrupan aquellas obras menos ortodoxas sin perder totalmente su relación con la gráfica tradicional. Pero aunque no incluyan adjetivo o sustantivo alguno para calificarse, como la prestigiosa Bienal de Ljubljana, sus propuestas suelen desatar polémicas sobre la esencia de la disciplina. Pastor Mellado (2005) llegó a denominar estos eventos como el "espacio ruinificado del grabado" y les achaca haber perdido el último bastión mostrando exposiciones de grabado que "no siendo grabados se postulan a seguir siendo denominados grabados" (Mellado, 2005: IV). Concretamente se refería a las X y XII Muestras de grabado de Curitiba (Brasil), la Trienal de Poligrafía de San Juan (Puerto Rico) y otras exposiciones brasileñas.

La figura del comisario macla a toda una comunidad miscelánea bajo un parámetro contemporáneo y/o de vanguardia en el que artistas, galeristas y público, conforman un mosaico aparentemente bien ensamblado con mayor o menor tolerancia a la transgresión. Los agentes culturales seleccionan los artistas que deben adaptar su lenguaje a un espacio y un discurso determinado, lo que supone cierto riesgo de que se conviertan en meros ilustradores de la teoría del curador. Todos los parámetros estéticos son susceptibles de ser cuestionados.

Este tipo de acontecimientos artísticos son los principales responsables de la evolución que se ha producido en la hechura gráfica y se encargan de la labor de transición que puede concluir definitivamente en la transformación de las ferias de grabado en ferias de arte contemporáneo. Si analizamos los cuatro últimos años de la Feria Internacional de Arte Múltiple Estampa, puede leerse esta evolución en las sucesivas declaraciones de su director, desde 2010, Chema de Francisco:

Si Estampa no es capaz de atraer al público, la feria no funciona. Estos años atrás estaba perdiendo sentido al no terminar de ponerse al día en su concepción general, al no valorar su enorme potencial ni utilizar las herramientas de comunicación del mercado del arte de hoy (De Francisco, 2011).

El grabado se ha ido viendo acompañado por otros procedimientos de elaboración de imágenes que están más cerca del ciudadano de hoy: los medios de comunicación, la publicidad, el cine... los artistas hoy en día trabajan con herramientas digitales, fotografía, vídeo o sonido de una forma más convincente para el que espera reflexión de una obra de arte (Berástagui, De Francisco, 2012).

Una serie de secciones vinculadas con el mundo del libro, de la edición, pero también con la ilustración y el texto con la animación a través del vídeo y con el dibujo extendido en el espacio, con las instalaciones de dibujo (De Francisco, 2013). 
Y en la última edición ha tenido cabida la pintura sobre papel, el dibujo contemporáneo, la fotografía, obra gráfica, video, los libros de artista, la ilustración, el arte sonoro, el diseño y las nuevas formas de edición de arte contemporáneo. Lo que empezó hace veintidós años como un salón dedicado a la venta de grabado se ha convertido en una feria que abarca todo tipo de técnicas de arte múltiple.

"Estampa" mantiene su nombre porque es una marca y poco más, y somos nosotros los que la conducimos de un lado hacia otro, hacia la realidad (De Francisco, 2014).

\section{Convergencia entre gráfica y cultura visual}

Hace ya más de una década que se puso en circulación el término estampa digital que respondió al desarrollo tecnológico producido en el campo de la imagen impresa. Un punto de partida importante en el caso español fue la exposición que realizó La Calcografía Nacional de título Estampa digital: la tecnología digital aplicada al arte gráfico al final de los noventa. Gómez Isla decía:

En aquel momento tuvimos la sensación de estar asistiendo a un mestizaje singular entre disciplinas hasta entonces irreconciliables. Sin embargo, en esta muestra convivian sin aparentes conflictos medios tan dispares como el grabado tradicional, la infografía, la fotografía o incluso la propia escultura generada por ordenador (Gómez Isla, 1998).

Si durante más de quinientos años la comunicación ha sido predominantemente textual por las limitaciones técnicas de la imprenta, ahora nos encontramos justo en el lado opuesto: la imagen prevalece sobre el texto; es más asequible y más directa.

Brea (2010) distingue tres etapas muy claras en la constitución de la imagen: aquella de imagen-materia como las artes plásticas o la fotografía; la imagen perteneciente al cine, o imagen fílmica caracterizada por el movimiento y la narración y por último la e-imagen o imagen electrónica caracterizada por ser autorreferencial, de consumo efímero y vigencia limitada. Este tipo globaliza el concepto de matriz y elimina, o disloca por su omnipresencia, el concepto de serie. Vemos una influencia constante de lo digital como origen para la realización de las estampas y una convergencia decidida hacia lo digital como momento exclusivo de la gráfica.

Desde el punto de vista artístico hoy en día pocos grabadores pueden ser definidos como tal. Nos referimos con el término "grabador" a aquellos artistas que se dedican exclusivamente a las técnicas más específicas del área dentro del campo analógico, esto es: xilografía, calcografía, serigrafía, litografía y todas sus variantes. La cultura visual que afecta al grueso de la sociedad no está dividida, ni lejanamente, por las disciplinas tradicionales del campo de las Bellas Artes y estas materias van perdiendo actualidad disolviéndose en el campo general de la imagen.

Por otro lado, lo que ahora parece sorprender, en poco tiempo será aceptado con normalidad encarnado en un formato distinto. Se trata de algo similar a lo que Pierre Bourdieu llamaría "atentados simbólicos" contra el orden establecido, es decir, lo que fue escándalo, se convertirá en norma. Para la persistencia de esta disciplina, no se trata tanto ya de hacer un grabado llamativo, un montaje conceptual o una performance que deje eco en la bienal más experimental, sino crear la institución gráfica con la 
suficiente poética en su discurso para que mueva el sentimiento humano. En este momento de liberación es probable que desaparezca por pura fusión con el resto de actividades artísticas, una especie de implosión en la que lo visual recoja lo gráfico. Dice Baudrillard:

Nada (ni siquiera Dios) desaparece ya por su final o por su muerte, sino por su proliferación, contaminación, saturación y transparencia, extenuación y exterminación, por una epidemia de simulación, transferencia a la existencia secundaria de la simulación. Ya no un modo fatal de desaparición, sino un modo fractal de dispersión (Baudrillard, 2006: 10).

Pero es conveniente insistir en una postura acogedora que anime a los artistas a que encuentren el punto de convergencia entre la tradición e invención, en caso contrario, la persistencia de la gráfica puede verse seriamente comprometida. En palabras de Octavio Paz,

Convergencia no quiere decir compromiso ecléctico sino conjunción de los contrarios. El arte de nuestros días está desgarrado por dos extremos: un conceptualismo radical y un formalismo no menos estricto. El primero niega la forma, es decir, a la substancia misma del arte, a su dimensión sensible; la obra artística no es nada si no es algo que vemos, oímos, tocamos: una forma. El segundo es una negación de la idea y la emoción. Ambas son versiones distintas, no pocas veces seductoras, del mismo vértigo ante el vacío. Este es el desafio al que se enfrentan los artistas contemporáneos. (Moro, 2012:140).

\section{Academia}

Mientras que en el ámbito artístico estas inquietudes son bienvenidas, en el ámbito académico se produce cierta incomodidad ante el panorama de tener que actualizar toda una complicada maquinaria administrativa, de infraestructuras y de actualización del profesorado. El propio significado de Academia, entendida como sociedad científica y artística de autoridad, exige que todo lo nuevo haya de referenciarse en un conjunto de teorías ya estabilizadas, por lo que cualquier discurso ideológico se toma el doble de tiempo para asentarse. Actualmente muchas facultades obligadas por la realidad social, las tendencias tecnológicas y una coyuntura favorable de remodelación de planes de estudio han reaccionado bien, aunque con otro tempo, a este reto. Solo queda conectar de forma más eficiente el ámbito académico con el social y el investigador con el productivo. Respondiendo a esta modernización y ante la reducción horaria del llamado Plan Bolonia el grabado ha sucumbido frente a asignaturas digitales en la mayoría de los centros. En aquellos en que perdura con una fuerte presencia parece tener un creciente anhelo de renovación. Ya no es extraño ver máquinas fotográficas y plotters compartiendo espacio con los tórculos, rodillos y pantallas en el taller; es una cuestión económica que las impresoras 3D y las cortadoras láser lleguen mientras que el Wi-Fi ya lo invade todo. Será una cuestión de tiempo que todas estas máquinas, bien utilizadas, aporten su significado en la reflexión artística de esta comunidad tan compleja. 


\section{Conclusiones}

Conforme a la época actual, la gráfica ha concedido gran parte de su espacio gráfico a las nuevas tecnologías de la imagen. Esto le ha permitido operar en vertientes distintas superando las dos dimensiones y operando más en el concepto que en el proceso. Ante el retroceso del apartado manual el conceptualismo crece: importa ahora más lo que se dice que cómo se dice.

Esto ha permitido la renovación de los formatos expositivos confiriéndole una expansión que es analizada de continuo por los teóricos de la gráfica. Lo trans, inter y post medial acompañan al desarrollo del grabado para fundirse con el resto del arte contemporáneo. En este proceso, la reivindicación propia de la sociedad actual transterra la objetualidad de la estampa que comienza a integrarse en discursos altamente complejos. El grabado, como objeto artístico contemporáneo, ha consumido gran parte de su valor.

Los circuitos de distribución encargados de esta renovación son las bienales, trienales y festivales oficiales que se conforman bajo la supervisión de un comisario. Las modas y la transgresión reiterada a lo establecido es un foco común en lo que lo poligráfico y lo experimental comienza a ser usual. Parte de la gráfica contemporánea es un producto dentro de la cultura visual en el que lo plástico, en ocasiones, puede quedar eclipsado por la rotundidad del mensaje que transmite. Lo arquitectónico, como lugar de vida, sobrepasa vastamente otras temáticas argumentales. Lo sublime, lo insólito y lo melancólico han sucedido al momento pop vivido durante la década de los 90 y los primeros años del milenio.

Se observan discrepancias entre la producción y la reflexión: el mercado y un sector de los academicistas parecen sujetar el aspecto más hiperestetizado de la gráfica mientras que los artistas, poco dispuestos a las limitaciones, avanzan por otros campos más afines a la cultura visual contemporánea.

La gráfica actual funciona por proyectos complejos que exigen una minuciosa ideación. La experimentalidad y la improvisación han dado lugar al diseño y la reflexión. El siglo XXI se reconoce por el dominio de un tipo de imagen ubicua y transversal a todos los territorios artísticos.

\section{Referencias}

Alcalá, J. R. (2006). "Explorando el laberinto. Gráfica, estampa y grabado en la sociedad digital", en Grabado y Edición. Art Print Edition Magazine, pp. 6-16.

Baudrillard, J. (1993). La transparencia del mal (Ensayo sobre los fenómenos extremos). Barcelona: Anagrama.

Beuys, J. Schellman, J., Klüser B. (Ed.). (1997). Joseph Beuys: The Multiples. USA: Harvard University Art Museums, Walker Art Center \& Schellmann Edition.

Blas, J. (2006). Arte Gráfico? La crisis de una categoría, Grabado y Edición, 1, pp. 6-9

Brea, J.L. (2006). Estética, Historia del Arte, Estudios Visuales, Estudios Visuales, 3 , Recuperado de http://estudiosvisuales.net/revista/index.htm

Brea, J.L. (2010). Las tres eras de la imagen: imagen-materia, film, e-image. Madrid: Akal. 
Casanueva Rocha, C. Caro González, F. J. (2013). La Academia Española de Comunicación: productividad científica frente a actividad social. Comunicar, 21(41), pp. 61-70. Doi: : http://dx.doi.org/10.3916/C41-2013-06

Cherix, C., Conaty, K. (2012). Print/Out: 20 Years in Print. MoMA Publications: New York.

Crespo B. (2014). El Libro de Artista de ayer a hoy: seis ancestros del Libro de Artista contemporáneo. Primeras aproximaciones y precedentes inmediatos, Arte, Individuo y Sociedad, 26 (II), 311-328. doi: http://dx.doi.org/10.5209/rev_ ARIS.2014.v26.n2.41347

Davis, F. (2005). El grabado en el "paisaje de las comunicaciones". Intercambios y préstamos entre la obra gráfica y los medios de comunicación en los primeros 70, (I Congreso Iberoamericano de Investigación Artística y Proyectual (CIDIAP) Recuperado de http://sedici.unlp.edu.ar/bitstream/handle/10915/40832/ Documento_completo.pdf?sequence $=1$

De Francisco Guinea, Ch., Berástagui, P. (2012, octubre, 10). Así es Estampa 2012, Hoy es Arte, recuperado de http://www.hoyesarte.com/entrevistas/c154-gestores/ asi-sera-estampa-2012 101975/

De Francisco Guinea, Ch. (2013, octubre, 13). [hoyesarte] Así es Estampa 2013 [Archivo de Video] recuperado de https://www.youtube.com/watch? $\mathrm{v}=\mathrm{tKvPxbcH}$ 7Vw\&list=PLlyiNoxGH9mL7RzeLdrzrgE31f5YNMjk3\&index $=6$

De Francisco Guinea, Ch. (2014, noviembre, 12). Chema de Francisco: No podemos mantenernos en una fórmula que se agota., Arte informado, recuperado de http://www.arteinformado.com/magazine/n/chema-de-francisco-no-podemosmantenernos-en-una-formula-que-se-agota-4368

Dixon, S. (2007). Digital performance: a history of new media in theater, dance, performance art and installation. Cambridge: MA. MIT Press

Donegan, Ch. [daphny david] (2010, ago. 18). Kiss my Royal Irish Ass (K.M.R.I.A). [Archivodevideo] recuperadodehttp://www.youtube.com/watch? $\mathrm{v}=2 \mathrm{yhnXanr} 8 \mathrm{~F} 0$

Enguita Mayo, N. (2014). Las bienales como referencia de la creación contemporánea: la Bienal de Sao Paulo. Sevilla: Facultad de Bellas Artes, Universidad de Sevilla. (Inédito)

Emmons E., Andrew Wandless, P., Resnick, M., Powers Nowlin, K. \& Frisch, S. (2008). Interview of Nicola Lopez; Linocuts and Clay; 2007 China Sanbao International Printmaking Exhibition, Symposium and Tour, Graphic Impressions, Summer Fall, North Carolina: Journal of Southern Graphics Council, recuperado de http://www.printeresting.org/2008/10/13/nicola-lopez-re-printerview/

Espejo, B. (2011, diciembre, 02). Chema de Francisco: "Estampa ya no es el Salón de Grabado" El Cultural, Recuperado de http://www.elcultural.es/noticias/arte/ Chema-de-Francisco-Estampa-ya-no-es-el-salon-de-grabado/2246

Galindo, R. J. [Performance Art Archive] (2012, junio, 3). ¿Quién puede borrar las huellas? [Archivo de video]. Recuperado de https://www.youtube.com/ watch? $\mathrm{v}=$ SDTLipg9vMc

Galindo, R. J. (s.f) Entrevista por Reilly, M. Elizabeth A. Sackler Center for Feminist Art: Feminist Art Base: Regina José Galindo recuperado de

https://www.brooklynmuseum.org/eascfa/feminist_art_base/gallery/reginajose.ph 
Gibson, J. J. (1966). The senses considered as perceptual systems. Boston: Hougton Mifflin.

Gómez Isla, J. Imagen digital: lecturas híbridas, Universo fotográfico, 1, Madrid: Departamento de Dibujo II, Universidad Complutense

Ingráfica (2010). Reproducción, repetición y reivindicación, recuperado de http:// www.hablarenarte.com/es/proyecto/id/reproduccion-repeticion-y-reivindicacion

Ivins, W. M. (1975). Imagen impresa y conocimiento: análisis de la imagen prefotográfica. Barcelona: Gustavo Gili

Krauss, R. (1979). Sculpture in the expanded field, October, 8, pp. 30-44.

Kupferminc, M., Sosnowski, M. [tallerdeimagen]. (2012, mayo, 20). En camino [Archivo de video] Recuperado de https://www.youtube.com/ watch? $\mathrm{v}=\mathrm{VpI} 15 \mathrm{UfkbnI} \# \mathrm{t}=10$

Leamy, J. [John Leamy] (2013) Nei, Need [Archivo de Video] recuperado de http:// vimeo.com $/ 59584642$

Lee, K. [Kakyoung Lee] (2011). Dance, dance, dance [Archivo de video] Recuperado de http://vimeo.com/31863057

McAndrew, C. (2014) El mercado español del arte en 2014. Barcelona, Fundación Arte y Mecenazgo (Cuadernos Arte y Mecenazgo ${ }^{\circ}$ 03). Recuperado de http:// fundacionarteymecenazgo.org/wp-content/uploads/2014/11/El-mercado-espa-ol-del-en-2014-Arte-y-Mecenazgo-Clare-McAndrew.pdf

Martínez Moro, J. (2008). Un ensayo sobre grabado (A principios del siglo XXI). México: Escuela Nacional de Artes Plásticas UNAM:

Mendez Llopis, C. (2010). Gráfica viva: aplicaciones de la imagen múltiple en el mundo contemporáneo. Actas de Diseño, 9, pp 187-191 Recuperado de http://fido. palermo.edu/servicios_dyc/publicacionesdc/archivos/148_libro.pdf

Papapetros, S. y Rose, J. (2014) Retracing the Expanded Field. Encounters between Art and Architecture. Massachusetts: The MIT Press,

Pastor Bravo, J. (2011) Sobre la identidad del Grabado, Libro de Actas de I Foro de Arte Múltiple, pp. 63-72, recuperado de http://www.estampa.org/web/wp-content/ uploads/downloads/2012/12/Actas_Foro_AM.pdf

Pastor Mellado, J. (2005). El concepto de desplazamiento en el grabado. Informe de campo III Recuperado http://www.justopastormellado.cl/edicion/index.php?optio $\mathrm{n}=$ content\&task $=$ view\&id $=186 \&$ Itemid $=28$

Pastor Mellado, J. (2005). El concepto de desplazamiento en el grabado. Informe de campo IV. Recuperado http://www.justopastormellado.cl/edicion/index.php?opti on $=$ content \& task $=$ view $\&$ id $=187 \&$ Itemid $=28$

Paz, O. (1979). Obra Gráfica Internacional 1971-1979, Actualidad Gráfica- Panorama Artístico. Artes de Mexico, 199, pp. 12

Paz, O. (1996). El grabado latinoamericano, en Sombras de Obras. Barcelona: Seix Barral 1996, p 188

Rodríguez Naranjo, L. [Laura Rodríguez] (2012). Circuitos sonoros. Grabado interactivo. Laura R.N. [Archivo de Video]. Recuperado de http://vimeo. com/49107538

Sánchez, V. [Curumin] (2013, sep., 25). Afoxoque - Curumin (Videoclip oficial) [Archivo de Video] Recuperado de https:/www.youtube.com/watch?v=OWGmLQr12Y 
Shiau, V. [kunstartamhellweg] (2010, feb., 10). Borned in URSS [Archivo de video] Recuperado de https://www.youtube.com/watch?v=P91NwL5LIGw

Soler Baena, A. (2011). (Coord) Libro de Actas I Foro de Arte Múltiple, Estampa Arte Múltiple: $19^{\text {a }}$ Feria Internacional de Arte Múltiple Contemporáneo.

Tala, A. (2009). Moving Image. En Tala, A. (Ed.) Installations and experimental printmaking. Huntingdon: A \&Black, pp 96-100

Weiwei, A. (2012). Print/Out Exhibition, New York, MOMA recuperado de http:// www.moma.org/interactives/exhibitions/2012/printout/category_works/ai weiwei/

Winkleman, E. (2009). How to Start and Run a Commercial Art Gallery. New York: BISAC Recuperado de http://www.edwardwinkleman.com/2012/09/what-do-wemean-by-dialog.html 